\title{
EVOLUTION OF NOBIRU COAST AT DECADAL TO CENTENNIAL SCALES INCLUDING THE 2011 TSUNAMI IMPACT
}

\author{
Hitoshi Tanaka, Tohoku University, Japan, hitoshi.tanaka.b7@tohoku.ac.jp \\ Nguyen Xuan Tinh, Tohoku University, Japan, nguyen.xuan.tinh.c5@tohoku.ac.jp \\ Vo Cong Hoang, Thuyloi University, Vietnam, hoangdht183@gmail.com
}

\section{INTRODUCTION}

Nobiru Coast, which is $2.8 \mathrm{~km}$ long coast located in Miyagi Prefecture, Japan, is a well-known coast because of high sediment deposition rate (Figure 1). The predominant littoral drift of this coast is from east to west (Takahashi and Tanaka, 2005). The sediment deposit at the western end causes significant effect on the aquaculture in Matsushima Bay which is located on the right of Miyato Island, due to closure of a channel connecting open sea and Matsushima Bay.

Tanaka et al. (2006) reported the sediment deposition rate on this coast from historical maps. The tsunami, which occurred on 11 March 2011, caused different types of damage on the left and right-hand sides of the coast. Accordingly, this study would evaluate the change of shoreline on Nobiru Coast at decadal to centennial scales including the 2011 tsunami impact using aerial and satellites images.

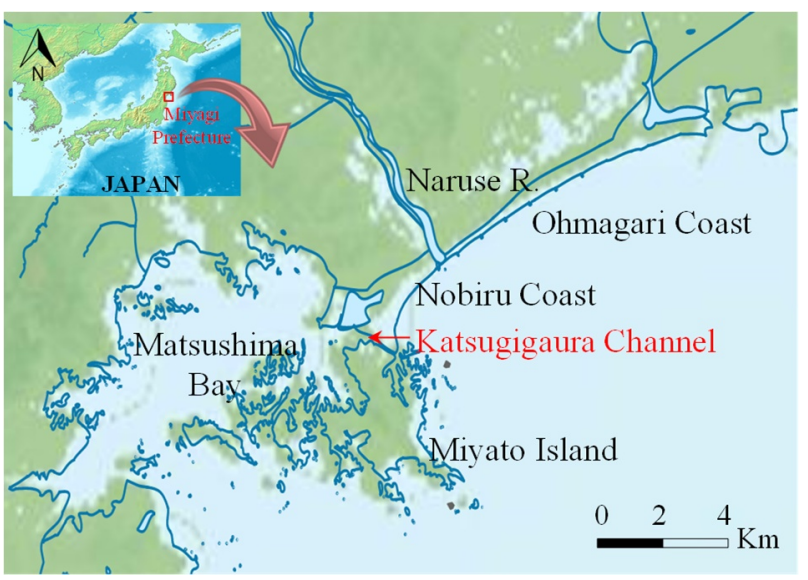

Figure 1 - Map of study area

\section{MORPHOLOGICAL RECOVERY AFTER THE 2011} TSUNAMI

Figure 2 shows aerial satellite images of Nobiru Coast from the Naruse River mouth to the Miyato Island before and after the 2011 tsunami. The beach on the right-hand side of the coast was washed away seriously by the tsunami, whereas the left one had no significant change. Tanaka et al. (2012) revealed that this difference of erosion is induced by structure type difference behind the sandy coast; serious erosion in riprap structure area and no erosion in concrete structure area.

Figure 3 presents the temporal variation of shoreline position at some transections. The severe damage shoreline gradually recovered after the severe retreat.

\section{LONGSHORE SEDIMENT TRANSPORT RATE}

The longshore sediment transport rate, $Q$, is quantified using Eq. (1).

$$
Q=\frac{\mathrm{d} A}{\mathrm{~d} t}\left(D_{B}+D_{C}\right)
$$

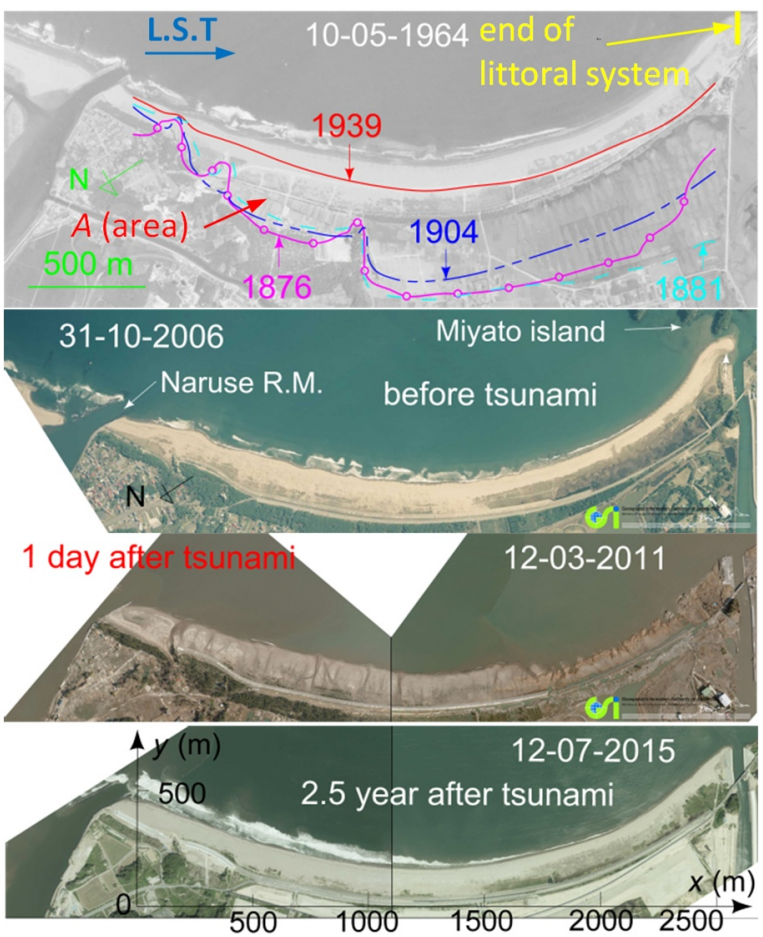

Figure 2 - Aerial and satellite images of study area

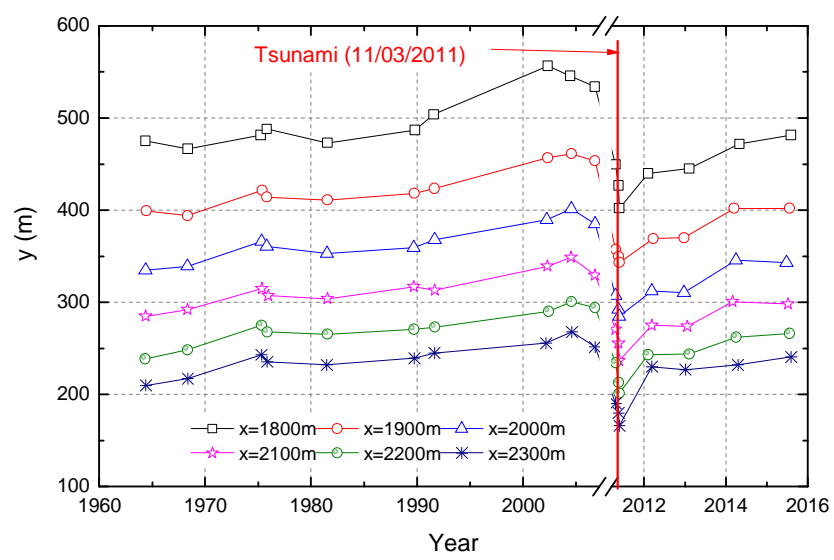

Figure 3 - Temporal variation of shoreline position

where $A$ is the change of sandy beach area as compared with first shoreline position in 1801, $t$ is the time, $D_{B}$ is the berm height and $D_{C}$ is the depth of closure. Result shown in Figure 4(a) indicates that the longshore sediment transport rate in the period from 1964 to 2006 reduced about $60 \%$ compared to the one in the previous period reported by Tanaka et al. (2006). The possible reason can be related to the reduction of sediment supply from river. However, that rate in the period after 
the tsunami is just a little bit smaller than that before the tsunami (more exaggerated in Figure 4(b)). That explains the gradual recovery of the coast after the tsunami.

\section{INFLUENCE OF SEDIMENT DEPOSIT ON TIDAL EXCAHANGE IN MATSUSHIMA BAY}

A water channel, called Katsugigaura Channel, is located in the right-hand end of Figure 1 and Figure 5 (a). The channel has been artificially excavated early in the 1960s in order to promote tidal exchange in Matsushima Bay, especially aiming improvement of deteriorated bay water in the northeast area of the bay, which had been induced by overproduction of aquacultured oyster.

However, due to remarkable rate of sediment deposition on Nobiru Coast, the seaward end of Katsugigaura Channel had been blockaded in 2006 as seen in Figure 5 (b), resulting in weak tidal exchange through the channel. For this reason, an artificial excavating work had been implemented in 2008 at that time to facilitate sea water intrusion into the bay, though the excavated area had been quickly filled with sand due to predominant longshore sediment movement to the end of the littoral system. However, devastating tsunamiinduced flow in the landward direction caused removal of sediment deposit in this region as clearly seen in Figure 5 (c).

According to Figure 4 (b), the present amount of sediment corresponds to that during early 1980s as indicated by a blue arrow. Therefore, it can be roughly estimated that due to sandy coast erosion by the 2011 Tohoku Tsunami, the blockade of Katsugigaura Channel has been postponed by about 30 years. However, since the sandy coast is located at the end of a littoral system, it is inevitable that the blockade problem of the water channel will occur in future around 2040s.

\section{CONCLUSIONS}

The longshore sediment transport rate on Nobiru coast from 1964 to 2006 reduced about $60 \%$ compared to the one in the previous period. However, that rate does not change much in the period after the tsunami although severe damages could be observed. This result recommends that the effect on the aquaculture in Matsushima Bay due to sediment deposition on the west end of the coast will take place again.

\section{REFERENCES}

Takahashi, Tanaka (2005): Change in morphology and sediment budget in the vicinity of Ishinomaki Port. Proceedings of 3rd Asian and Pacific Coastal Engineering Conference, pp.931-942.

Tanaka, Takahashi, Matsutomi, Izumi (2006): Application of old maps for studying long term shoreline change, Proceedings of the 30th International Conference on Coastal Engineering, pp. 4022-4034.

Tanaka, Tinh, Umeda, Hirao, Pradjoko, Mano, Udo (2012): Coastal and estuarine morphology changes induced by the 2011 Great East Japan Earthquake Tsunami, Coastal Engineering Journal, Vol.54, No.1. (a)

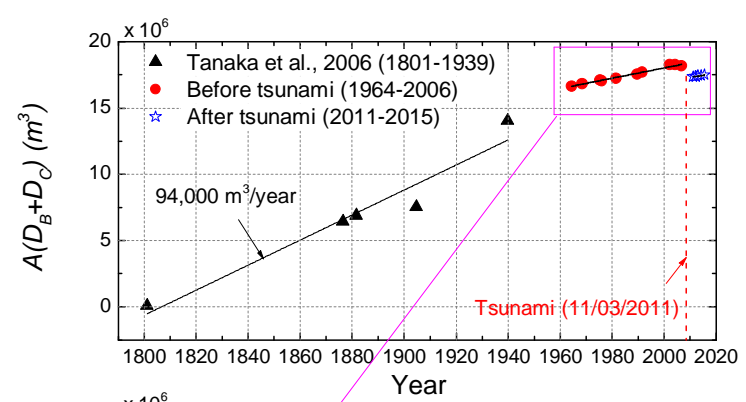

(b)

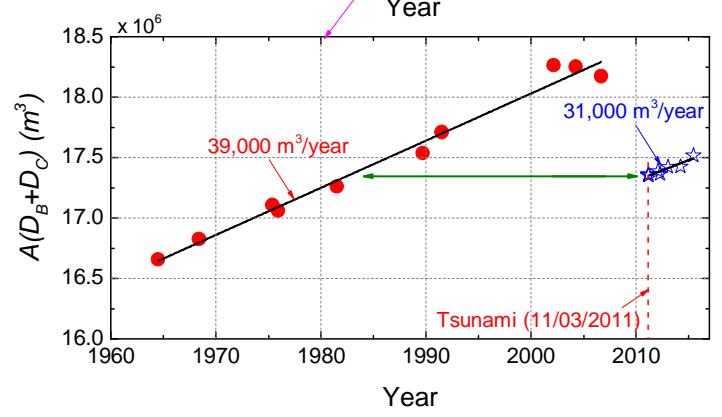

Figure 4 - Evaluation of deposited sediment
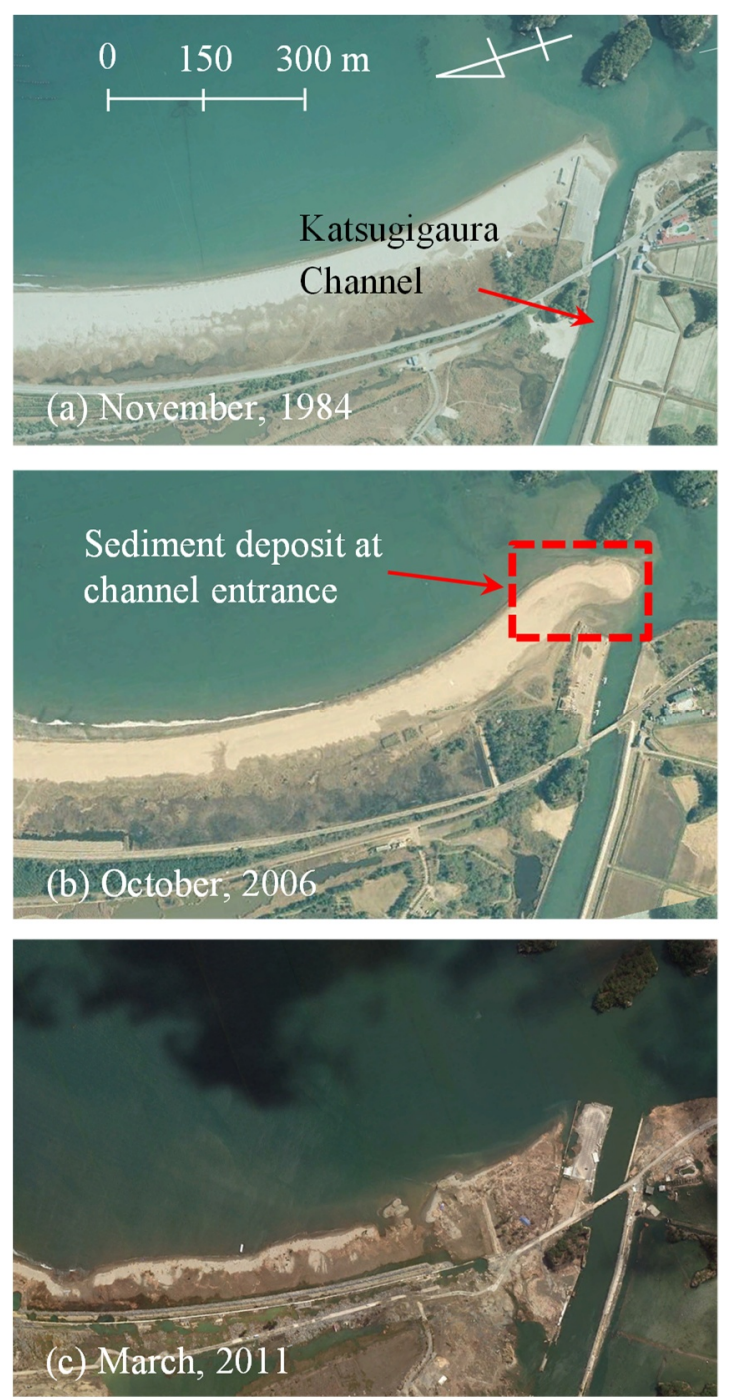

Figure 5 - Sediment deposit at the entrance of Katsugigaura Channel 